\title{
The Design of Focus Area Maturity Models
}

\author{
Marlies van Steenbergen ${ }^{1}$, Rik Bos ${ }^{2}$, Sjaak Brinkkemper $^{2}$, Inge van de Weerd ${ }^{2}$, \\ Willem Bekkers ${ }^{2}$
${ }^{1}$ Sogeti Netherlands, Wildenborch 3, 1112 XB Diemen, The Netherlands Marlies.van.Steenbergen@sogeti.nl
${ }^{2}$ Department of Information and Computing Sciences, Utrecht University, Padualaan 14, 3584 CH Utrecht, The Netherlands
\{R.Bos, S.Brinkkemper, I.vandeWeerd, Bekkers $\} @$ cs.uu.nl

\begin{abstract}
Maturity models are a well-known instrument to support the improvement of functional domains in IS, like software development or testing. In this paper we present a generic method for developing focus area maturity models based on both extensive industrial experience and scientific investigation. Focus area maturity models are distinguished from fixed-level maturity models, like CMM, in that they are especially suited to the incremental improvement of functional domains.
\end{abstract}

Keywords: Design Research Methodology, Design Science, Enterprise Architecture, Software Product Management, Maturity Model.

This paper has been published as: Steenbergen, M. van, Bos, R, Brinkkemper, S, Weerd, I, van de, Bekkers, W.: The Design of Focus Area Maturity Models. In: W R. Winter, J.L. Zhao, and S. Aier (eds.): DESRIST 2010, LNCS 6105, pp. 317-332, Springer-Verlag Berlin Heidelberg (2010).

Within the field of IS new functional domains, like enterprise architecture and software product management, are still emerging. Developing such functional domains is a complex matter. Decisions have to be made about how and in what order to develop new processes, deliverables and competences. Maturity models are a wellknown instrument to support incremental development of functional domains, as they distinguish different maturity levels that an organization progresses through.

In this paper we present a generic method to develop a particular kind of maturity model, the focus area maturity model. The focus area maturity model is particularly well-suited to support incremental development of functional domains as it departs from the concept of having a limited fixed number of generic maturity levels as used in CMM. Instead it defines maturity levels, called capabilities, per focus area within the functional domain. By juxtaposing all capabilities of all focus areas of a domain relative to each other, a balanced, incremental development path is defined. This juxtaposition of capabilities is done by positioning the capabilities in a matrix as shown in figure 1 , which gives an example of a focus area maturity model in the functional domain of enterprise architecture. The capabilities are depicted by the letters A to D. Each capability is associated with a number of checkpoints. An architecture profile of a specific organization can be depicted by coloring the cells up to the capability that has not been implemented yet. The architecture profile provides 
insight into the strengths and weaknesses of the domain and where to focus improvement actions.

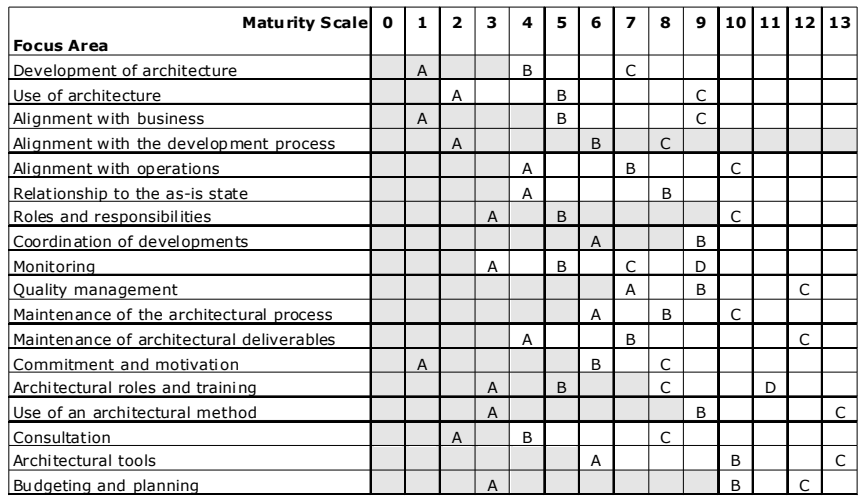

Fig. 1. A focus area maturity model for the functional domain of enterprise architecture.

Applying design science research methodology [1], we developed a generic method for developing focus area maturity models, depicted in figure 2.

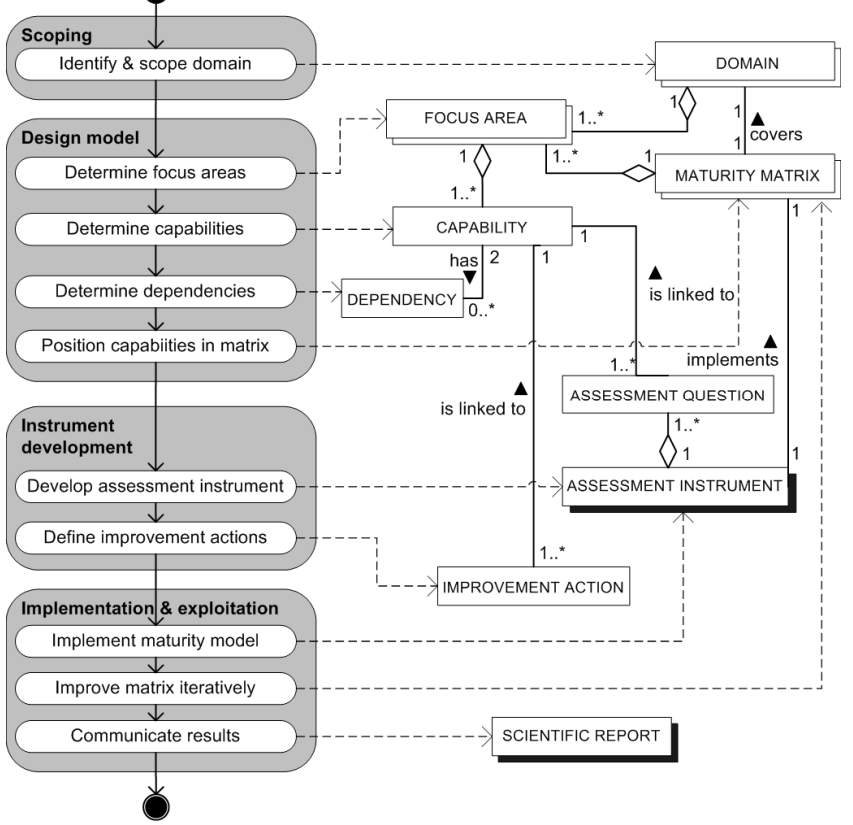

Fig. 2. The development method for focus area maturity models.

The development method is based on both literature review [2, 3, 4, 5] and extensive industrial experience in applying the focus area maturity model concept [6, $7,8,9]$. The concept of the maturity matrix is refined by building a mathematical formalization of the matrix. 


\section{References}

1. Peffers, K., Tuunanen, T., Rothenberger, M.A., Chatterjee, S.: A Design Science Research Methodology for Information Systems Research. Journal of Management Information Systems, vol.24 (3), pp. 45-78 (2008)

2. Bruin, T. de, Freeze, R., Kulkarni, U., Rosemann, M.: Understanding the Main Phases of Developing a Maturity Assessment Model. In: Proceedings of the 16th Australasian Conference on Information Systems. Sydney (2005)

3. Mettler, T., Rohner, P.: Situational Maturity Models as Instrumental Artifacts for Organizational Design. In: Proceedings of the 4th international Conference on Design Science Research in information Systems and Technology. Philadelphia (2009)

4. Maier, A.M., Moultrie, J., Clarkson, P.J.: Developing Maturity Grids for Assessing Organisational Capabilities: Practitioner Guidance. In: 4th International Conference on Management Consulting, Academy of Management (MCD'09). Vienna (2009)

5. Becker, J., Knackstedt, R., Pöppelbuß, P.: Developing Maturity Models for IT Management - A Procedure Model and its Application. Business \& Information Systems Engineering 1(3), pp. 213-222 (2009)

6. Steenbergen, M. van, Berg, M. van den, Brinkkemper, S. A Balanced Approach to Developing the Enterprise Architecture Practice. In: Filipe, J., Cordeiro, J., Cardoso, J. (eds.) Enterprise Information Systems. LNBIP 12, pp. 240-253 (2007)

7. Steenbergen, M. van, Schipper J., Bos, R, Brinkkemper, S: The Dynamic Architecture Maturity Matrix: Instrument Analysis and Refinement. To appear in the proceedings of the $4^{\text {th }}$ Workshop on Trends in Enterprise Architecture Research. Stockholm (2009)

8. Bekkers, W., Spruit, M., Weerd, I. v., Brinkkemper, S.: A Situational Assessment Method for Software Product Management. To appear in ECIS2010 proceedings (2010)

9. Weerd, I, van de, Bekkers, W., Brinkkemper, S.: Developing a Maturity Matrix for Software Product Management. To appear in Jansen, S., Tyrvainen, P. (eds.) Proceedings of the 1st International Conference on Software Business. LNBIP 51, Jyväskylä (2010) 